\title{
Effect of Patient's Personality on Satisfaction with Their Present Complete Denture and after Increasing the Occlusal Vertical Dimension: A Study of Edentulous Egyptian Patients
}

\author{
Shaimaa M. Fouda, ${ }^{1}$ Mohamed S. Al-Attar, ${ }^{2}$ Jorma I. Virtanen, ${ }^{3,4}$ and Aune Raustia ${ }^{4,5}$ \\ ${ }^{1}$ Department of Substitutive Dental Sciences, College of Dentistry, Dammam University, P.O. Box 1982, Dammam 31411, Saudi Arabia \\ ${ }^{2}$ Department of Prosthodontics, Faculty of Dentistry, Alexandria University, P.O. Box 21500, Alexandria, Egypt \\ ${ }^{3}$ Department of Community Dentistry, Institute of Dentistry, University of Oulu, P.O. Box 5281, 90014 Oulu, Finland \\ ${ }^{4}$ Oral and Maxillofacial Department, Oulu University Hospital, Finland \\ ${ }^{5}$ Department of Prosthetic Dentistry and Stomatognathic Physiology, Institute of Dentistry, \\ University of Oulu, P.O. Box 5281, 90014 Oulu, Finland
}

Correspondence should be addressed to Shaimaa M. Fouda; shaimaa.fouda@hotmail.com

Received 17 April 2014; Revised 8 June 2014; Accepted 23 June 2014; Published 8 July 2014

Academic Editor: Claudio R. Leles

Copyright (C) 2014 Shaimaa M. Fouda et al. This is an open access article distributed under the Creative Commons Attribution License, which permits unrestricted use, distribution, and reproduction in any medium, provided the original work is properly cited.

\begin{abstract}
Complete denture wearers often find it difficult to accept a new denture. Personality traits are among the factors that possibly affect patient satisfaction with a complete denture. Our aim was to investigate the influence of patients' personality on satisfaction with their present denture and after an increase in the occlusal vertical dimension (OVD). Sixty edentulous patients with complete dentures ( 22 men and 38 women, mean age 66 years, and range 50-75 years) participated in the study. The age of their complete dentures ranged from 5 to 16 years. Patients' personalities were evaluated using the Arabic version of the Eysenck Personality Questionnaire. Their satisfaction with their dentures before and after restoration of the OVD and relining of the mandibular denture was evaluated using two questionnaires (I and II), Patients with a high score of neuroticism were less satisfied with their original dentures and after relining and an increase of OVD compared with patients with an average score in that trait. The personality trait of psychoticism was significant to patients' acceptance of an increase in OVD; that is, patients with a high score were less satisfied with their dentures after increase of OVD than patients with an average score. It is concluded that personality traits affect patients' acceptance of their complete dentures.
\end{abstract}

\section{Introduction}

The prevalence of edentulism has decreased during the last decades, especially in developed countries. However, the level of edentulism is still high in developing countries [1-3]. In addition, more people worldwide are advancing into old age and a growing number of edentulous people are expected [1]. Edentulism has a deep impact on the quality of life, affecting individuals' physiological, biological, social, and psychological state [4]. It can also cause a state of depression due to disturbances in speech, esthetics, mastication, and a feeling of inferiority because an important part of the person has been lost [5].
Conventional complete dentures are still the treatment of choice in many cases for both economic and biological reasons [6]. However, a considerable proportion of denture wearers are dissatisfied with their complete dentures [7]. Several studies investigated factors that may affect patients' satisfaction with their complete dentures, such as denture technical quality, condition of the residual ridges, and patient's gender, age, previous denture experience, and personality $[5,6,8]$. Conflicting results have been reported regarding associations with denture acceptance; yet emotional and psychological factors seem to play an important role in acceptance of complete dentures $[4,5]$. The use of a removable denture depends on the patient's ability to adapt 
to the function of the dentures as well as adaptation at the emotional level $[5,6]$.

The relationship between patient's personality and denture satisfaction has been investigated and inconsistent findings were reported, regarding the relationship between personality and denture satisfaction [4-6, 9]. Several questionnaires have been used to assess patients' personality, for example, the shortened version of the Minnesota Multiphasic Personality Inventory (MMPI) [9], the Cornell Medical Index (CMI) [10], Cattell's 16PFQ form C questionnaire [11], the Revised Personality Inventory (NEO PI-R) [5], the Eysenck Short Scale Personality Questionnaire (EPQ-R) [12-15], and the Eysenck Personality Inventory (EPI) [16]. It has been noted that some personality traits like neuroticism influence patient satisfaction with a removable denture $[5,10-12,16,17]$.

Long-time complete denture wear often results in reduced occlusal vertical dimension due to residual ridge resorption and acrylic tooth wear. This is especially true for the mandible [18]. Restoring the OVD is an important treatment procedure in prosthetic treatment, especially in edentulous patients [19].

The aim of our study was to investigate the effect of the patients' personality on satisfaction with their present complete dentures and after an increase in the OVD by using the Arabic version of the EPQ for personality assessment. The hypothesis of the study was that personality traits were expected to have an effect on the patients' satisfaction with the present dentures and after an increase in the OVD.

\section{Materials and Methods}

Sixty completely edentulous patients with maxillary and mandibular complete dentures in use ( 22 men and 38 women, mean age 66 years, and range $50-75$ years) who were seeking prosthetic treatment for relining of their old dentures or fabrication of new ones were selected from the Department of Prosthodontics, Faculty of Dentistry, Alexandria University, Egypt, in 2009-2011. All patients who had complete dentures with a reduced OVD and an interocclusal rest space of no more than $10 \mathrm{~mm}$ participated in the study after giving their informed consent. The age of their complete dentures ranged from 5 to 16 years (mean 9 years). The patients included had one or more mild signs of temporomandibular disorders (TMD), that is, masticatory muscle pain during palpation or headache. Patients with temporomandibular joint (TMJ) clicking and patients with a significant restriction in opening movement of the mandible were excluded [20]. Patients with a systemic disease that possibly affects the masticatory system, for example, rheumatoid arthritis or epilepsy, were also excluded from the study. The study was approved by the Research Ethical Committee, Faculty of Dentistry, Alexandria University.

The patients were recalled for three visits after the first visit at two-week intervals (see Figure 1). All sixty patients completed the study.

2.1. The First Visit. Patient history was recorded. A clinical stomatognathic examination was performed, including measurement of the opening movement of the mandible and recording of TMJ sounds, TMJ pain, and/or pain in the masticatory muscles during palpation [21]. The interocclusal rest space was determined by calculating the difference between rest vertical dimension determined phonetically and OVD with the two-dot technique using a ruler [22]. The patients' personality was assessed by using the Arabic version of the Eysenck Scale Personality Questionnaire [23]. All the patients were interviewed by the same psychologist, who presented the questionnaire to the patients and recorded their answers. The questionnaire consisted of 90 questions with yes/no answers, and it yielded scores for each of the major personality traits: psychoticism, extrovertism, neuroticism, criminality, and lie scale. The patient's attitude toward his/her present dentures before relining and restoration of the OVD was determined by asking questions related to chewing efficiency, speech, and overall satisfaction (Questionnaire I) [24]. Chair-side relining of poorly fitting mandibular denture was done using self-curing acrylic resin (Hardliner, PROMEDICA, Neumünster, Germany) [22, 25].

2.2. The Second and Third Visits. The OVD was restored gradually, $2 \mathrm{~mm}$ during the second visit and up to $5 \mathrm{~mm}$ during the third visit, according to the interocclusal rest space of each patient, by applying autopolymer acrylic resin to the occlusal surfaces of the posterior teeth of the mandibular denture [18] (SNAP Parkell, NY, USA).

2.3. The Fourth Visit. Evaluation of the patients' denture satisfaction after restoration of the OVD was assessed using a second comparative questionnaire (Questionnaire II) [24]. An independent interviewer, who did not participate in the clinical examination or the treatment procedures, presented Questionnaires I and II to the patients. The interviewer read each question to the patient and recorded the patient's answers. All the clinical examinations and treatment procedures were performed by the same dentist specialized in prosthetic dentistry (SMF).

2.4. Statistical Analysis. The Statistical Package for Social Sciences (SPSS/version 17) software was used for data analysis. The Chi-square test served for analysis of categorical data and comparison of the patients' satisfaction and different personality traits.

\section{Results}

Table 1 shows the patients' overall satisfaction with their complete dentures at the first appointment. Two-thirds (73\%) of the patients showed slight to complete dissatisfaction with their dentures. Most of the patients (83\%) used their dentures always/almost always for eating, although $70 \%$ of them mostly/frequently experienced chewing discomfort and $67 \%$ rarely felt it easy to chew hard food. Over half (53\%) of the patients experienced pain in their jaws and $58 \%$ reported jaw aching or stiffness in the morning. After restoration of the OVD and denture relining, the patients' perception of their dentures showed improvement in chewing ability (67\%) and chewing comfort (53\%), and they perceived also improvement in chewing hard food (52\%) (Table 2). The patients also reported improvement in jaw aching or stiffness in the morning (27 patients) as well as in jaw pain (19 patients). 


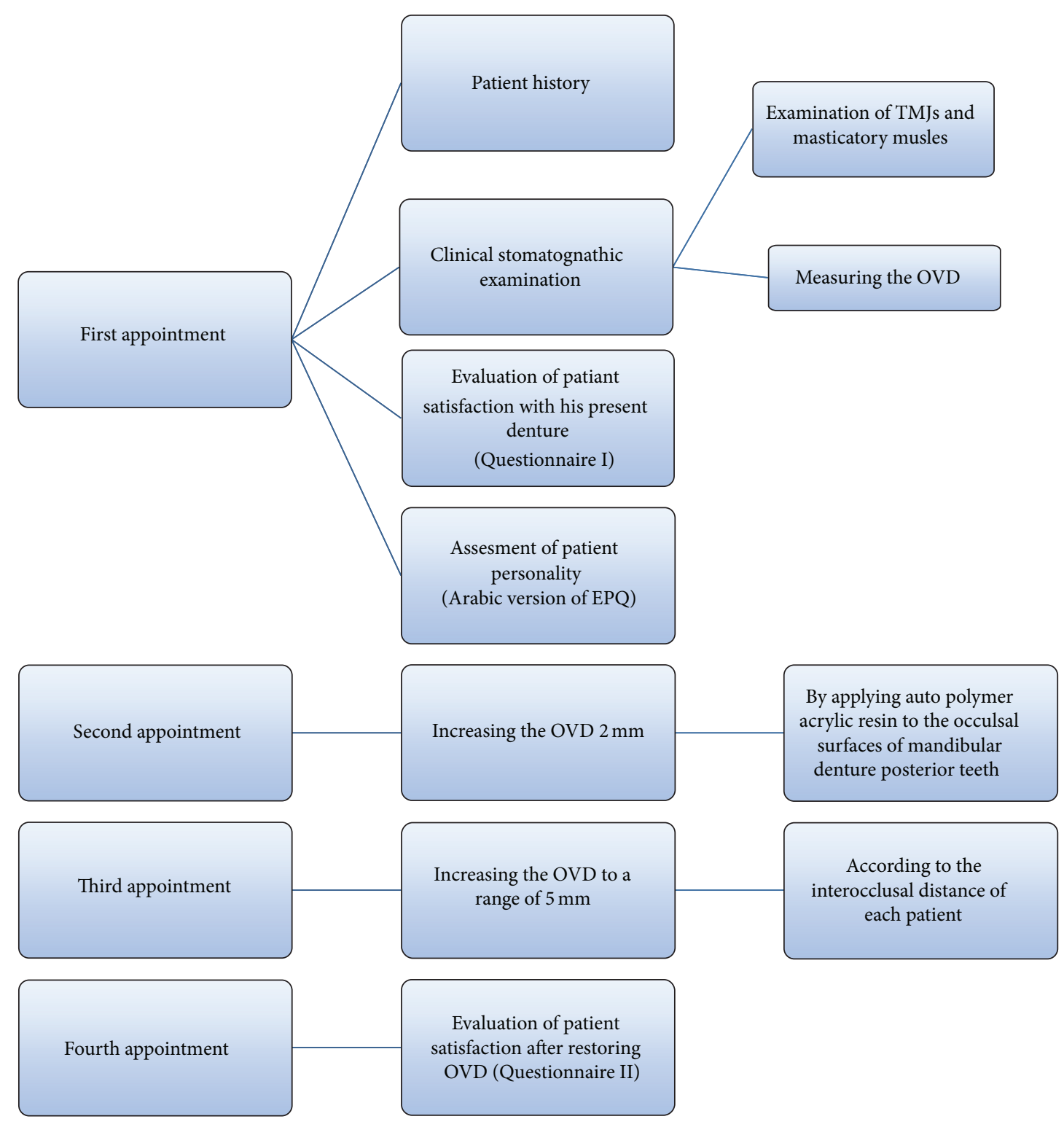

FIGURE 1: Patients were recalled for three visits after first appointment at two-week intervals (OVD: occlusal vertical dimension).

When the levels of satisfaction with the original dentures before and after dentures relining and restoration of the OVD were compared, a significant increase in the patients' satisfaction was observed $(P<0.05)$ (Table 3$)$. Neuroticism correlated with the patients' satisfaction with their original dentures before and after restoration of the OVD and relining $(P<0.05)$. Two-thirds $(29 / 44,66 \%)$ of the patients who were unsatisfied with their original denture had a high score on neuroticism, while all the satisfied patients had an average neuroticism score (Table 4). No correlation between personality traits of psychoticism and extrovertism and the patients' satisfaction with their original denture was seen (Table 4). After an increase in the OVD and relining, a significant association between the level of the patients' satisfaction and psychoticism was observed $(P<0.05)$. Of the unsatisfied patients $(n=12), 10$ had a high score on psychoticism (Table 5). After denture relining and restoration of the OVD, 12 patients were unsatisfied with their dentures and nine of them had a high score on neuroticism (Table 5).

\section{Discussion}

In the present study a significant increase in the patients' satisfaction after chair-side relining of poorly fitting mandibular dentures and restoration of the OVD was observed. Our results confirm the findings of previous studies showing that dissatisfaction with dentures in addition to the retention and stability of the dentures is maybe associated with emotional instability or neuroticism [10-12, 16, 17]. Psychological factors can affect patients' acceptance of a denture, and therefore a personality assessment could be beneficial in predicting satisfaction with a complete denture [5].

This result agrees with the finding of the previous studies, which found that most patients with a modified denture 
TABLE 1: Patients' $(n=60)$ satisfaction with their original complete dentures based on their answers to Questionnaire I.

\begin{tabular}{|c|c|c|c|c|}
\hline Question & Mostly & Frequently & Occasionally & Rarely \\
\hline (1) Eating with dentures & $83 \%$ & $17 \%$ & $0 \%$ & $0 \%$ \\
\hline (2) Experience chewing discomfort & $62 \%$ & $8 \%$ & $30 \%$ & $0 \%$ \\
\hline (3) Ease of chewing hard food & $0 \%$ & $10 \%$ & $23 \%$ & $67 \%$ \\
\hline (4) Eating enjoyment & $48 \%$ & $20 \%$ & $17 \%$ & $15 \%$ \\
\hline (5) Affect food choices & $68 \%$ & $8 \%$ & $14 \%$ & $10 \%$ \\
\hline (6) Food particles under dentures & $91 \%$ & $7 \%$ & $2 \%$ & $0 \%$ \\
\hline (7) Taste (difference) & $33 \%$ & $38 \%$ & $17 \%$ & $12 \%$ \\
\hline (8) Speech (difficulties) & $36 \%$ & $25 \%$ & $22 \%$ & $17 \%$ \\
\hline (9) Dentures odor changed & $37 \%$ & $20 \%$ & $17 \%$ & $26 \%$ \\
\hline (10) Cleaning difficulties & $25 \%$ & $17 \%$ & $25 \%$ & $33 \%$ \\
\hline (11) Cleanliness & $20 \%$ & $22 \%$ & $25 \%$ & $33 \%$ \\
\hline (12) Security & $8 \%$ & $12 \%$ & $17 \%$ & $63 \%$ \\
\hline \multicolumn{5}{|l|}{ (13) Satisfaction } \\
\hline Slightly, moderately, or completely satisfied & \multicolumn{4}{|c|}{$27 \%$} \\
\hline Slightly, moderately, or completely dissatisfied & \multicolumn{4}{|c|}{$73 \%$} \\
\hline (14) Jaw ache or stiffness mourning & $13 \%$ & $20 \%$ & $25 \%$ & $42 \%$ \\
\hline (15) Pain in jaw & $20 \%$ & $13 \%$ & $20 \%$ & $47 \%$ \\
\hline
\end{tabular}

TABLE 2: Patients' $(n=60)$ satisfaction with their complete dentures after restoring OVD and relining based on their answers to Questionnaire II.

\begin{tabular}{|c|c|c|c|c|c|c|c|}
\hline Question & -3 & -2 & -1 & 0 & 1 & 2 & 3 \\
\hline (1) Chewing ability & $13.3 \%$ & $3.3 \%$ & $13.3 \%$ & $3.3 \%$ & $20.0 \%$ & $16.7 \%$ & $30.0 \%$ \\
\hline (2) Chewing comfort & $16.7 \%$ & $5.0 \%$ & $20.0 \%$ & $5.0 \%$ & $25.0 \%$ & $18.3 \%$ & $10.0 \%$ \\
\hline (3) Ease of chewing hard food & $18.3 \%$ & $3.3 \%$ & $16.7 \%$ & $10.0 \%$ & $20.0 \%$ & $16.7 \%$ & $15.0 \%$ \\
\hline (4) Food choices & $11.7 \%$ & $3.3 \%$ & $16.7 \%$ & $8.3 \%$ & $16.7 \%$ & $25.0 \%$ & $18.3 \%$ \\
\hline (5) Eating enjoyment & $11.7 \%$ & $6.7 \%$ & $11.7 \%$ & $5.0 \%$ & $20.0 \%$ & $21.7 \%$ & $23.3 \%$ \\
\hline (6) Cleaning & $5.0 \%$ & $10.0 \%$ & $28.3 \%$ & $8.3 \%$ & $13.3 \%$ & $15.0 \%$ & $20.0 \%$ \\
\hline (7) Cleanliness & $10.0 \%$ & $5.0 \%$ & $18.3 \%$ & $16.7 \%$ & $15.0 \%$ & $13.3 \%$ & $21.7 \%$ \\
\hline (8) Odor & $8.3 \%$ & $5.0 \%$ & $16.7 \%$ & $26.7 \%$ & $16.7 \%$ & $16.7 \%$ & $10.0 \%$ \\
\hline (9) Odor frequency & $13.3 \%$ & $6.7 \%$ & $16.7 \%$ & $15.0 \%$ & $16.7 \%$ & $8.3 \%$ & $23.3 \%$ \\
\hline (10) Security & $6.7 \%$ & $3.3 \%$ & $20.0 \%$ & $6.7 \%$ & $13.3 \%$ & $13.3 \%$ & $36.7 \%$ \\
\hline (11) Speech & $10.0 \%$ & $8.3 \%$ & $18.3 \%$ & $21.7 \%$ & $10.0 \%$ & $11.7 \%$ & $20.0 \%$ \\
\hline (12) Jaw ache or stiffness & $11.7 \%$ & $5.0 \%$ & $21.7 \%$ & $16.7 \%$ & $5.0 \%$ & $5.0 \%$ & $35.0 \%$ \\
\hline (13) Pain in jaws & $16.7 \%$ & $10.0 \%$ & $16.7 \%$ & $25.0 \%$ & $8.3 \%$ & $8.3 \%$ & $15.0 \%$ \\
\hline
\end{tabular}

TABle 3: Patients' $(n=60)$ satisfaction with their original complete dentures, and after relining and restoration of the OVD.

\begin{tabular}{lccccc}
\hline $\begin{array}{l}\text { Level of } \\
\text { satisfaction }\end{array}$ & \multicolumn{2}{c}{ Original denture } & $\begin{array}{c}\text { After restoring } \\
\text { VDO }\end{array}$ & $P$ value \\
& Number & $\%$ & Number & $\%$ & \\
\hline Satisfied & 6 & 10 & 33 & 55 & \\
Neutral & 10 & 17 & 15 & 25 & 0.0013 \\
Unsatisfied & 44 & 73 & 12 & 20 & \\
\hline
\end{tabular}

perceived improvement or no change $[24,26]$. Most patients with old dentures accepted a gradual increase in the OVD, even if they were used to their old dentures with a reduced OVD. This could also be explained by the improvement in chewing functions and the gradual increase in the OVD performed in this study, which might be tolerated better by the patients than an increase in one step [22].

The personality trait of psychoticism was not significantly related to patients' satisfaction with their original dentures. This was also reported in earlier studies [12, 27]. However, a high psychoticism score was related to patients' dissatisfaction after relining and restoration of the OVD of their old dentures. Psychoticism measures tough-mindedness. A person with a high psychoticism score tends to behave impulsively, being insensitive, aggressive, and finding it difficult to adapt $[28,29]$. Therefore, psychoticism had no effect on patients' satisfaction with their old dentures because they were used to them, while it affected their acceptance of a change in their dentures, that is, an increase in the OVD. Another explanation might be the evaluation of the patients' satisfaction with the increased OVD after only two weeks, which is a short period for patients with a high psychoticism 
TABLE 4: Association between the level of patients' satisfaction with their present complete dentures and psychoticism, neuroticism, and extroversion.

\begin{tabular}{|c|c|c|c|c|c|c|c|c|}
\hline & \multicolumn{2}{|c|}{ Satisfied } & \multicolumn{2}{|c|}{ Neutral } & \multicolumn{2}{|c|}{ Unsatisfied } & \multirow{2}{*}{ Total $(n)$} & \multirow{2}{*}{$P$ value } \\
\hline & $N$ & $\%$ & $N$ & $\%$ & $N$ & $\%$ & & \\
\hline \multicolumn{9}{|l|}{ Psychoticism } \\
\hline Low score & 0 & 0 & 0 & 0.0 & 0 & 0.0 & 0 & \\
\hline Average score & 6 & 20 & 2 & 7 & 22 & 73 & 30 & 0.21 \\
\hline High score & 0 & 0 & 8 & 27 & 22 & 73 & 30 & \\
\hline Total $(n)$ & \multicolumn{2}{|c|}{6} & \multicolumn{2}{|c|}{10} & \multicolumn{2}{|c|}{44} & & \\
\hline \multicolumn{9}{|l|}{ Neuroticism } \\
\hline Low score & 0 & 0 & 0 & 0 & 0 & 0 & 0 & \\
\hline Average score & 6 & 24 & 4 & 16 & 15 & 60 & 25 & 0.005 \\
\hline Highs core & 0 & 0 & 6 & 17 & 29 & 83 & 35 & \\
\hline Total $(n)$ & \multicolumn{2}{|c|}{6} & \multicolumn{2}{|c|}{10} & \multicolumn{2}{|c|}{44} & & \\
\hline \multicolumn{9}{|l|}{ Extroversion } \\
\hline Low score & 0 & 0 & 2 & 17 & 10 & 83 & 12 & \\
\hline Average score & 6 & 13 & 8 & 17 & 34 & 71 & 48 & 0.233 \\
\hline High score & 0 & 0 & 0 & 0 & 0 & 0 & 0 & \\
\hline Total $(n)$ & \multicolumn{2}{|c|}{6} & \multicolumn{2}{|c|}{10} & \multicolumn{2}{|c|}{44} & & \\
\hline
\end{tabular}

Average scores on

psychoticism: males $(\mathrm{M})=3.95( \pm 3.28)$ and females $(\mathrm{F})=2.77( \pm 2.54)$;

neuroticism: $\mathrm{M}=9.67( \pm 5.10)$ and $\mathrm{F}=12.73( \pm 5.07)$;

extroversion: $\mathrm{M}=13.12( \pm 4.95)$ and $\mathrm{F}=12.95( \pm 4.67)$.

TABLE 5: Association between the level of patients' satisfaction after relining and restoration of the OVD of their complete dentures and psychoticism, neuroticism, and extroversion.

\begin{tabular}{|c|c|c|c|c|c|c|c|c|}
\hline & \multicolumn{2}{|c|}{ Satisfied } & \multicolumn{2}{|c|}{ Neutral } & \multicolumn{2}{|c|}{ Unsatisfied } & \multirow{2}{*}{ Total $(n)$} & \multirow{2}{*}{$P$ value } \\
\hline & $N$ & $\%$ & $N$ & $\%$ & $N$ & $\%$ & & \\
\hline \multicolumn{9}{|l|}{ Psychoticism } \\
\hline Low score & 0 & 0 & 0 & 0 & 0 & 0.0 & 0 & \\
\hline Average score & 19 & 63 & 9 & 30 & 2 & 7 & 30 & 0.032 \\
\hline High score & 14 & 47 & 6 & 20 & 10 & 33 & 30 & \\
\hline Total $(n)$ & \multicolumn{2}{|c|}{33} & \multicolumn{2}{|c|}{15} & \multicolumn{2}{|c|}{12} & & \\
\hline \multicolumn{9}{|l|}{ Neuroticism } \\
\hline Low score & 0 & 0 & 0 & 0 & 0 & 0 & 0 & \\
\hline Average score & 20 & 80 & 2 & 8 & 3 & 12 & 25 & 0.039 \\
\hline High score & 13 & 37 & 13 & 37 & 9 & 26 & 35 & \\
\hline Total $(n)$ & \multicolumn{2}{|c|}{33} & \multicolumn{2}{|c|}{15} & \multicolumn{2}{|c|}{12} & & \\
\hline \multicolumn{9}{|l|}{ Extroversion } \\
\hline Low score & 10 & 83 & 0 & 0 & 2 & 17 & 12 & \\
\hline Average score & 23 & 48 & 15 & 31 & 10 & 21 & 48 & 0.225 \\
\hline High score & 0 & 0 & 0 & 0 & 0 & 0 & 0 & \\
\hline Total $(n)$ & \multicolumn{2}{|c|}{33} & \multicolumn{2}{|c|}{15} & \multicolumn{2}{|c|}{12} & & \\
\hline
\end{tabular}

score to adapt to a change in their dentures. This finding is in line with a study that found a presence of a difference in the relationship between personality profiles and satisfaction before and after treatment [30].

We found a significant relationship between high neuroticism scores and patient dissatisfaction. Patient neuroticism has been suggested as a negative indicator of complete denture success [31]. A person with a high neuroticism score has been described as being a worrying individual, frequently depressed, and overtly emotional and having a greater tendency to complain about his/her denture [27, 28]. Some studies have shown a significant negative association between neuroticism and patient satisfaction with a denture $[5,10$, $12,16]$. In addition, vague denture complaints and esthetic complaints about a bulbous face have been found to be related to neuroticism [23]. It has been noted that neuroticism remained the only trait that maintained a relationship with patients' satisfaction before and after treatment, while other personality profiles were found to be significantly related to satisfaction ratings after treatment [30]. Other studies found 
that dissatisfied patients may possess particular personality traits that influence their satisfaction with dentures. Although in these studies the personality trait of neuroticism was not measured, the findings are still in line with our results $[4,11]$.

Extroversion was not found to have a significant effect on the level of satisfaction. An extravert is characterized by being sociable, talkative, outgoing, cheerful, and optimistic; in contrast an introvert is overly careful, shy, pessimistic, and calm and dislikes company [28]. This result may be related to the relatively small number of patients with a low extroversion score. However, this finding agrees with the results of previous studies which suggested that extrovertism was not related to patient satisfaction with dentures [12, 27]. This finding disagrees with a study that found a relationship between the personality trait of extrovertism and functional complaints about the mandibular denture and complaints about a hollow face [17].

The Arabic version of the EPQ for assessment of patients' personality was utilized because of its validity and reliability in Egypt [23]. The EPQ is an effective personality measurement tool which analyzes the characteristics of personality structure [28]. The strengths of our study were that the personality assessments were done by the same psychologist, the questionnaires were presented to all the patients by the same interviewer, all the clinical procedures were performed by the same dentist, and all the patients completed the study. The limitations include a relatively small sample size and a lack of patients with a high extrovertism score, since the patients here do not represent the whole population.

\section{Conclusion}

It is concluded that personality traits affect patients' acceptance of a complete denture. Patients with a high score on neuroticism were less satisfied with their original dentures and after relining and an increase in the OVD compared with patients with an average score on that trait. A high psychoticism score was found to be related to patients' dissatisfaction after restoration of the OVD.

\section{Conflict of Interests}

The authors declare no conflict of interests regarding the publication of this paper.

\section{References}

[1] I. Polzer, M. Schimmel, F. Müller, and R. Biffar, "Edentulism as part of the general health problems of elderly adults," International Dental Journal, vol. 60, no. 3, pp. 143-155, 2010.

[2] B. Haikola, K. Oikarinen, A. L. Söderholm, T. Remes-Lyly, and K. Sipilä, "Prevalence of edentulousness and related factors among elderly Finns," Journal of Oral Rehabilitation, vol. 35, no. 11, pp. 827-835, 2008.

[3] H. E. Nazliel, N. Hersek, M. Ozbek, and E. Karaagaoglu, "Oral health status in a group of the elderly population residing at home," Gerodontology, vol. 29, no. 2, pp. e761-e767, 2012.

[4] A. K. Özdemir, H. D. Özdemir, N. T. Polat, M. Turgut, and H. Sezer, "The effect of personality type on denture satisfaction,"
International Journal of Prosthodontics, vol. 19, no. 4, pp. 364370, 2006.

[5] F. Al Quran, T. Clifford, C. Cooper, and P. J. Lamey, "Influence of psychological factors on the acceptance of complete dentures," Gerodontology, vol. 18, no. 1, pp. 35-40, 2001.

[6] E. Berg, "Acceptance of full dentures.", International Dental Journal, vol. 43, no. 3, pp. 299-306, 1993.

[7] A. M. Albaker, "The oral health-related quality of life in edentulous patients treated with Conventional complete dentures," Gerodontology, vol. 30, no. 1, pp. 61-66, 2013.

[8] M. R. Fenlon and M. Sherriff, "An investigation of factors influencing patients' satisfaction with new complete dentures using structural equation modelling," Journal of Dentistry, vol. 36, no. 6, pp. 427-434, 2008.

[9] M. Smith, "Measurement of personality traits and their relation to patient satisfaction with complete dentures," The Journal of Prosthetic Dentistry, vol. 35, no. 5, pp. 492-503, 1976.

[10] C. L. Bolender, C. C. Swoope, and D. E. Smith, "The Cornell Medical Index as a prognostic aid for complete denture patients," The Journal of Prosthetic Dentistry, vol. 22, no. 1, pp. 20-29, 1969.

[11] P. E. Reeve, C. J. Watson, and G. D. Stafford, "The role of personality in the management of complete denture patients," British Dental journal, vol. 156, no. 10, pp. 356-362, 1984.

[12] M. R. Fenlon, M. Sherriff, and J. T. Newton, "The influence of personality on patients' satisfaction with existing and new complete dentures," Journal of Dentistry, vol. 35, no. 9, pp. 744748, 2007.

[13] P. T. Barrett, K. V. Petrides, S. B. G. Eysenck, and H. J. Eysenck, "The Eysenck Personality Questionnaire: an examination of the factorial similarity of P, E, N, and L across 34 countries," Personality and Individual Differences, vol. 25, no. 5, pp. 805819, 1998.

[14] D. A. van Hemert, F. J. R. van de Vijver, Y. H. Poortinga, and J. Georgas, "Structural and functional equivalence of the Eysenck Personality Questionnaire within and between countries," Personality and Individual Differences, vol. 33, no. 8, pp. 1229-1249, 2002.

[15] T. Tiwari, A. L. Singh, and I. L. Singh, "The short-form Eysenck personality questionnaire: a Hindi edition (EPQRS-h)," Industrial Psychiatry Journal, vol. 18, pp. 27-31, 2009.

[16] A. D. Guckes, D. E. Smith, and C. C. Swoope, "Counseling and related factors influencing satisfaction with dentures," The Journal of Prosthetic Dentistry, vol. 39, no. 3, pp. 259-267, 1978.

[17] J. M. Vervoorn, A. S. Duinkerke, F. Luteijn, and A. C. van de Poel, "Relative importance of psychologic factors in denture satisfaction.," Community Dentistry and Oral Epidemiology, vol. 19, no. 1, pp. 45-47, 1991.

[18] K. A. Mays, "Reestablishing occlusal vertical dimension using a diagnostic treatment prosthesis in the edentulous patient: a clinical report," Journal of Prosthodontics, vol. 12, no. 1, pp. 3036, 2003.

[19] A. M. Raustia, M. Peltola, and M. A. M. Salonen, "Influence of complete denture renewal on craniomandibular disorders: a 1year follow-up study," Journal of Oral Rehabilitation, vol. 24, no. 1, pp. 30-36, 1997.

[20] T. L. Miller, R. W. Katzberg, R. H. Tallents, R. W. Bessette, and K. Hayakawa, "Temporomandibular joint clicking with nonreducing anterior displacement of the meniscus," Radiology, vol. 154, no. 1, pp. 121-124, 1985. 
[21] G. E. Carlsson and T. Magnusson, Management of Temporomandibular Disorders in the General Dental Practice, Quintessence Publishing, Berlin, Germany, 1999.

[22] R. M. Basker and Davenportm C. D., Prosthetic Treatment of the Edentulous Patient, Blackwell Munksgaard, 4th edition, 2002.

[23] A. Abdel-Khalik, Manual of the Arabic Version of the Eysenck Personality Questionnaire: Junior and Adults, Dar Al-Marrifa ElGameehea, Alexandria, Egypt, 1991 (Arabic).

[24] N. R. Garrett, K. K. Kapur, and P. Perez, "Effects of improvements of poorly fitting dentures and new dentures on patient satisfaction," Journal of Prosthetic Dentistry, vol. 76, no. 4, pp. 403-413, 1996.

[25] I. Hayakawa and S. Hirano, "A method to remold worn acrylic resin posterior denture teeth and restore lost vertical dimension of occlusion," The Journal of Prosthetic Dentistry, vol. 69, no. 2, pp. 234-236, 1993.

[26] S. Gamer, R. Tuch, and L. T. Garcia, "M. M. House mental classification revisited: intersection of particular patient types and particular dentist's needs," Journal of Prosthetic Dentistry, vol. 89, no. 3, pp. 297-302, 2003.

[27] R. I. Nairn and D. L. Brunello, "The relationship of denture complaints and level of neuroticism," The Dental Practitioner and Dental Record, vol. 21, no. 5, pp. 156-158, 1971.

[28] H. J. Eysenck and S. G. B. Eysenck, Administering the Questionnaires, Manual of the Eysenck Personality Scales, Stodder and Houghton, London, UK, 1991.

[29] H. J. Eysenck, "The definition and measurement of psychoticism," Personality and Individual Differences, vol. 13, no. 7, pp. 757-785, 1992.

[30] A. H. Ra’ed Omar, A. Mahmoud Khalid, and A. Ahed Mahmoud, "Psychological impact on implant patients' oral healthrelated quality of life," Clinical Oral Implants Research, vol. 17, no. 2, pp. 116-123, 2006.

[31] S. B. Critchlow and J. S. Ellis, "Prognostic indicators for conventional complete denture therapy: a review of the literature," Journal of Dentistry, vol. 38, no. 1, pp. 2-9, 2010. 


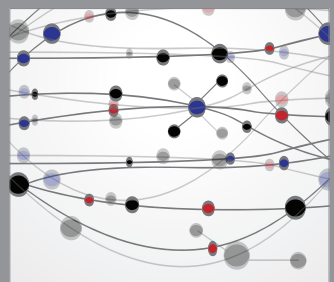

The Scientific World Journal
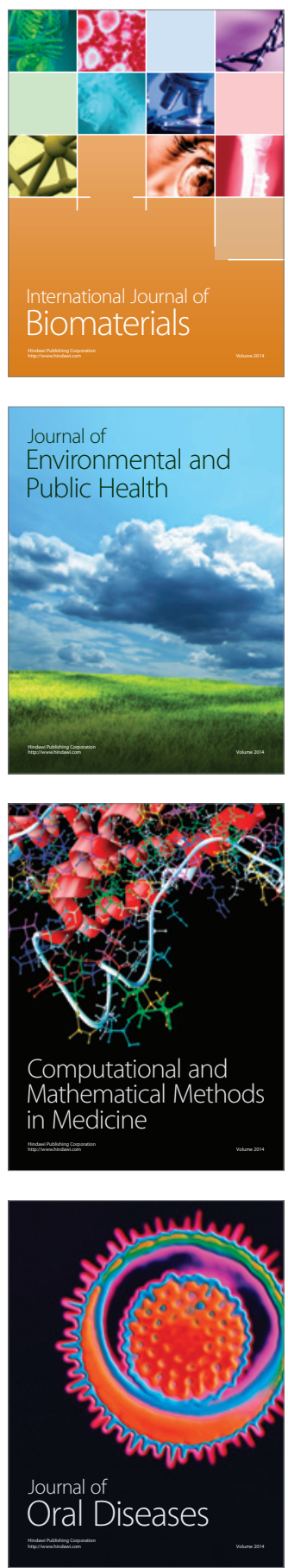
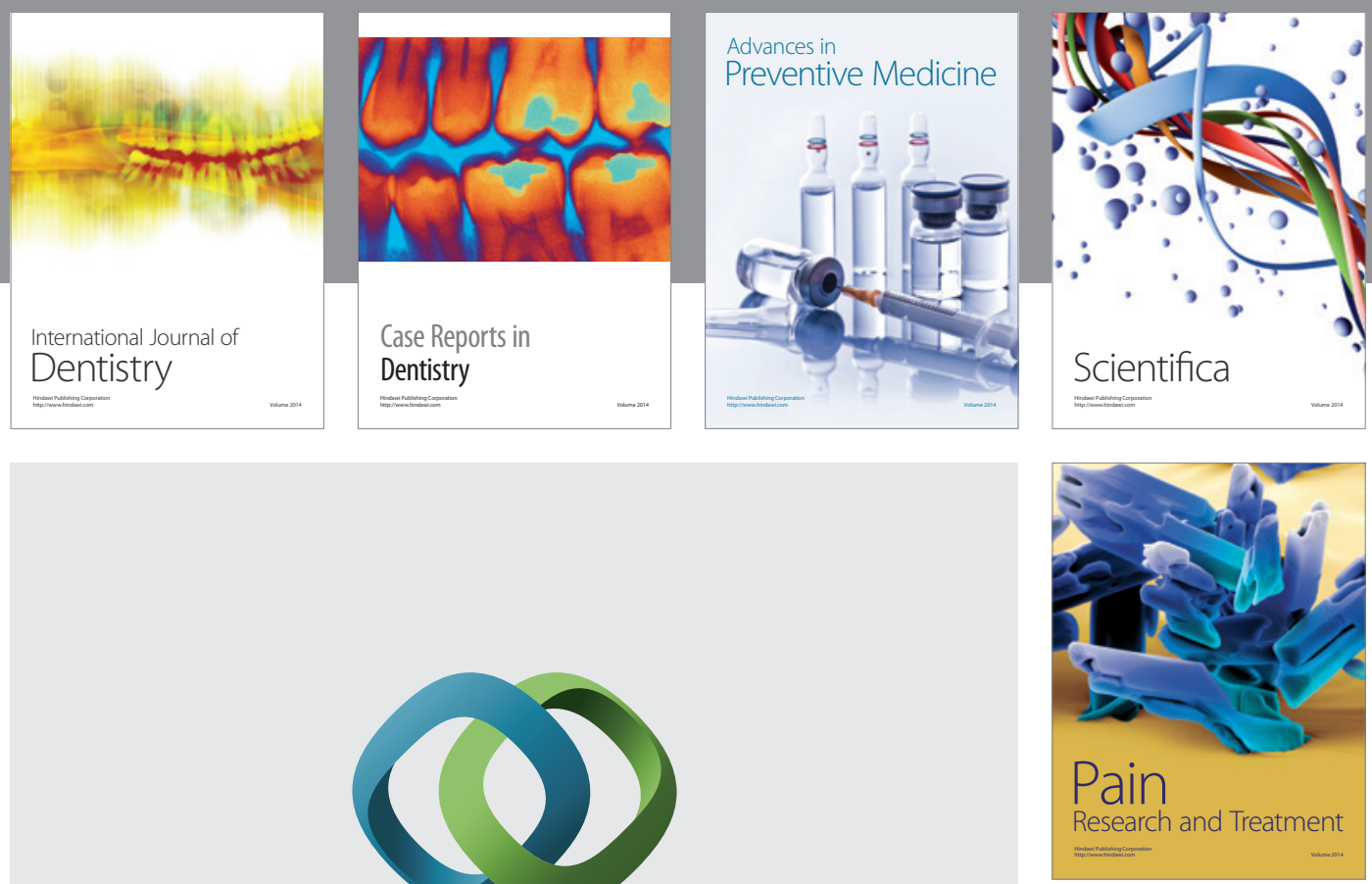

\section{Hindawi}

Submit your manuscripts at

http://www.hindawi.com
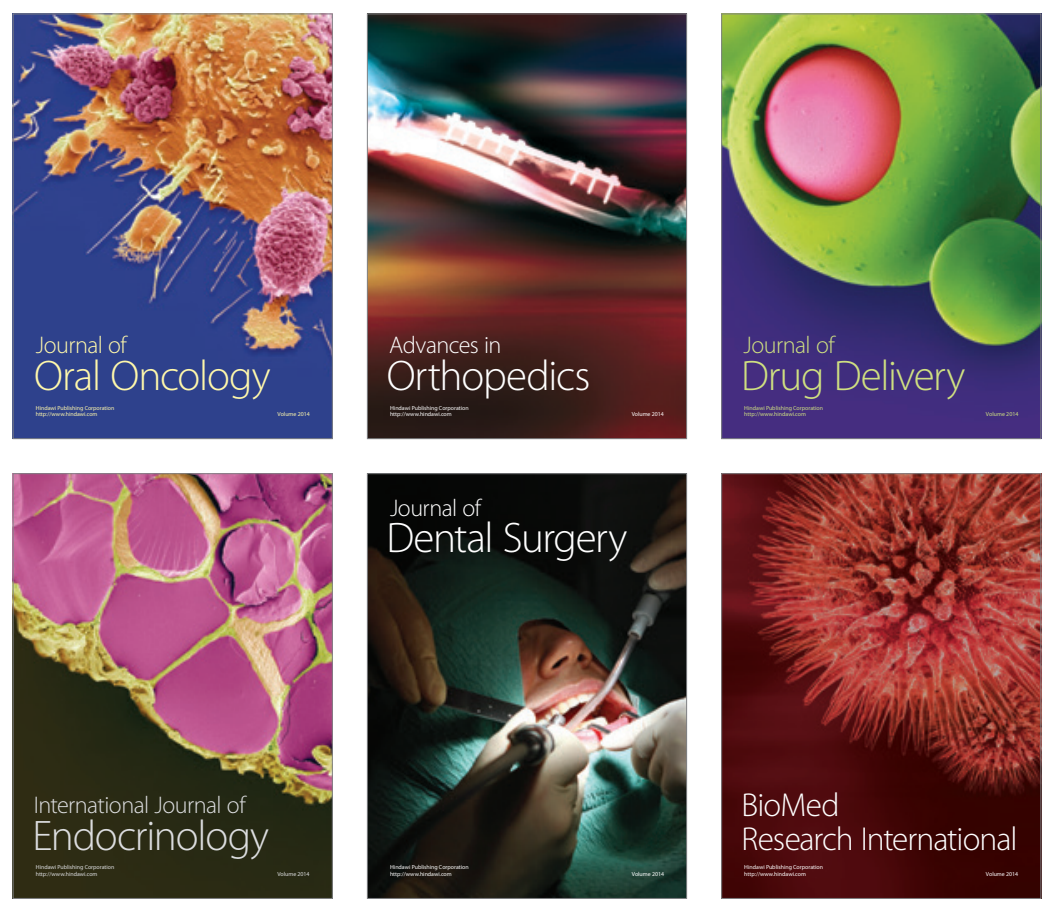

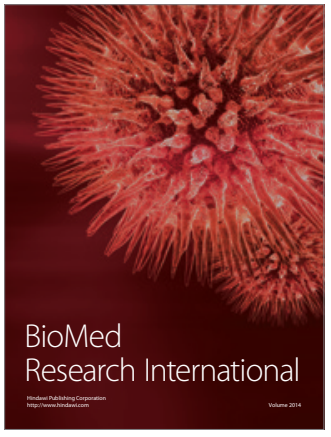

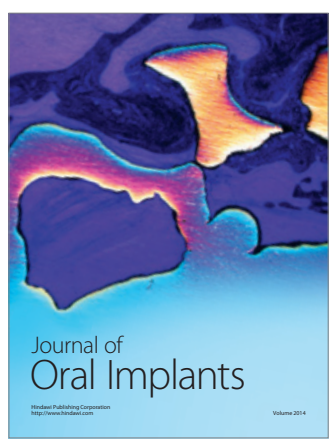
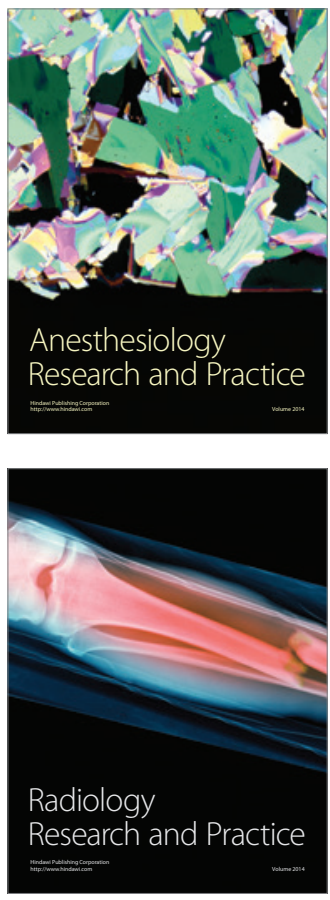